\title{
Employee Behavior Towards Adoption of E-learning Courses: Validating Technology Acceptance Model
}

\author{
Syed Afzal Moshadi Shah \\ Assistant Professor, Department of Management Sciences \\ COMSATS Institute of Information Technology, Abbottabad, Pakistan \\ afzalshah@ciit.net.pk \\ Naveed lqbal \\ Lecturer, Department of Management Sciences \\ COMSATS Institute of Information Technology, Abbottabad, Pakistan \\ naveed@ciit.net.pk

\section{Dr. Saquib Yusaf Janjua} \\ Assistant Professor, Department of Management Sciences \\ COMSATS Institute of Information Technology, Islamabad, Pakistan \\ saqib.yousaf@comsats.edu.pk

\section{Dr. Shehla Amjad} \\ Professor, Head, Department of Management Sciences \\ COMSATS Institute of Information Technology, Abbottabad, Pakistan \\ shehla@ciit.net.pk
}

Doi:10.5901/mjss.2013.v4n14p765

Abstract

The study aims to investigate the acceptability of e-learning courses for professional qualification offered by the Institute of Bankers Pakistan (IBP). The study is empirical in nature and has utilized data by 172 respondents received through online survey method technique. Technology Acceptance Model (TAM) is used to investigate the acceptance of e-learning. Descriptive statistics, correlation and regression analysis are used to reach the final analysis. Cronbach Alfa is used to measure the reliability of the survey. Research finding indicate promising prospects for introducing e-learning based courses. Learning style and age indicates positive association with Perceived Ease of Use whereas learning style alone is positively correlated with Perceived Usefulness.

Keywords: e-learning, Technology Acceptance Model (TAM), banking sector, Service Sector

\section{Introduction}

In the age of globalization, the use of digital technology has become inevitable for sustainable business success. Business industry around the world is creatively capitalizing upon the benefits offered by information and communication technology. So much so, the technology is being used to address soft issues that are related to human resource. Elearning is such an attempt made by organizations, in order to train their employees with the effective use of this technology. However, e-learning is still evolving and many organizations are still finding it difficult to find out the best fit for them. Sloman (2005) emphasized on hype created by e-learning stating "e-learning was aggressively promoted as a way of cutting the costs of training by replacing classroom events with modules delivered to the individual at his or her personal computer". But now according to Sloman (2005), "we have learned a lot and can now offer a more balanced picture of the place of e-learning based on particular experience".

The popularity of the technology acceptance research has trigged with the pace of technology has evolved over the period of time. Davis (1989) was the first to lay the corner stone of measuring the Technology Acceptance through 
his famous Technology Acceptance Model (TAM). This study attempts to investigate the prospects of introducing elearning based course for ISQ for the banking sector of Pakistan using TAM model.

ISQ is the most popular professional course for bankers in Pakistan, offered by the Institute of Bankers Pakistan (IBP). The course is a highly prestigious and famous for the bankers as it is recognized by the State Bank of Pakistan and other Financial Institutions. It is the desire of the majority of the bankers to qualify the course as it is directly linked with high promotions, increase salary, professional recognition, and increased chances of employability etc. This is the reason a large number of employee get themselves registered for this course. However, due to the demanding nature of the job and unavailability of qualified trainers may result in making several attempts to clear a course. This may result high failure, increased de-motivation and loss of time and resources. This study aims to investigate the prospects of elearning based ISQ. We believe that it would help students to learn effectively, increase their professional understanding and their other personal goals.

\section{Literature Review}

The popularity of the technology acceptance model (TAM) is evident through the massive use by researchers for learning about technology adoption and the use of information systems. (Straub et al, 1997). A meta-analysis study conducted by King and $\mathrm{He}$ (2006) provides some promising results of using technology acceptance model (TAM). The study incorporated 88 research articles and reported high credibility of TAM model. King and He (2006) termed TAM as a highly 'valid and robust model'. Straub et al's (1997) study raises some concerns over implementation of TAM across different cultures and understanding the adoption phenomena. The study shows TAM validity in Switzerland and United States and not in Japan.

Flett et al (2004) have moved one step ahead and have studied the applicability of TAM in the dairy farming in New Zealand. They found a close relationship between individuals Perceived Usefulness (PU) and Perceived Ease of Use (PEU) and their actual use of technology.

A recent study conducted by Pai \& Huangb (2011) proposes a conceptual framework for measuring the behavioral intention of using information system in the health care sector. The findings of the study indicate encouraging results towards the use of the proposed healthcare information system.

\subsection{E-learning}

Allen (2012) considers e-learning as a continuous process of experimentation and exploration over computing technology. Sloman defines e-learning as a learning that is delivered, enabled or mediated by electronic technology, for the explicit purpose of training in organizations (2005, p. 9). Webster (2005) defines e-leaning as any learning that occurs over the computer. Clark \& Mayer (2011) believe e-learning an instruction based delivery process on a digital device such as a computer or mobile device that is intended to support learning. No, doubt, e-learning has revolutionized the whole process of leaning, however, its exact name/title remains confusing. Some famous terminologies currently in use are e-learning; online learning; virtual learning; or distance learning (Pailing, 2002, p. 155). In a recent study conducted by ASTD (2010) shows that during 2009 the average percentage of learning per hour was 36.5 percent. The learning that took place online (both self-paced and instructor led) remained the major tool of e-learning with 27.7 percent. The reusability of the e-learning material during 2009 was 56.3 percent.

Despite effectiveness and opportunities created by e-learning facility threats and dangers to teachers and administrators remains there (Cheol, 2003). It is pivotal for countries like Pakistan, who yet have to explore the avenues of e-learning, to hold a realistic view about e-learning to gain maximum benefit out of this facility. For instance, the initial hype that e-learning will replace classroom based learning was later proved to be wrong, rather research has shown a very little difference between learning outcomes in both ways (Russell, 2005). The flexibility feature of e-learning provides learners a chance to self-paced learning, whereas affordance feature allows learners' to interact with objects and individuals spaced by time and distance (Ryder \& Wilson, 1996; Bell, 2007). Most of the multinational companies that uses e-learning have termed it an easier, highly cost effective, and efficient way of training employees (Bell, 2007). The benefits of e-learning, if capitalized upon properly can be huge. By training and have a full track of the employees progress in compliance-related issues such as disability and diversity discrimination and health and safety etc, would help organizations to remain legally correct.

Lee, Yoon \& Lee (2009) believes that e-learning has brought about a significant change from the conventional teacher-lead class room environment. In their view, a comprehensive study of the adoption of e-learning courses by 
students is urgently required.

Šumak, Heričko \& Pušnik (2011) have used meta-analysis technique to understand the existing knowledge on elearning technology acceptance. Figure 1 indicates the percentage of the usage of theories by the researchers in order to investigate the technology acceptance. Their major findings of the 42 independent studies are given below:

i) Technology Acceptance Model (TAM) is the most widely used technology acceptance theory

ii) The nature of the e-learning technology and the individual's nature severely affect the casual relationship between TAM variables.

Fig. 1: Theories applied in e-learning acceptance studies

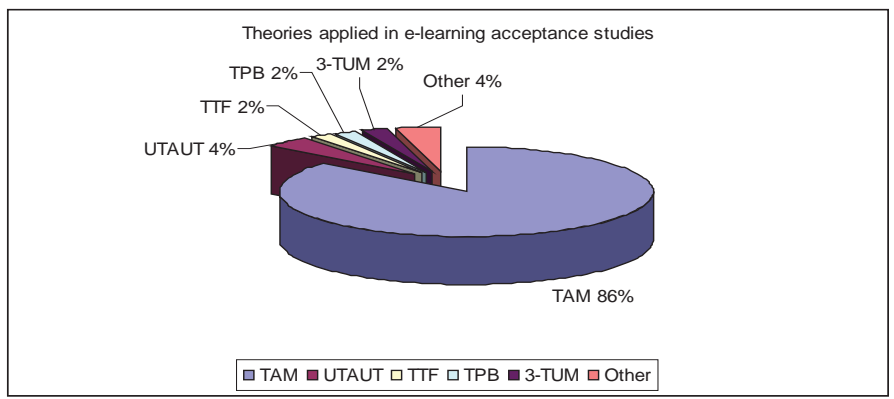

Source: Šumak, Heričko \& Pušnik (2011)

\subsection{History of e-learning in Pakistan:}

Allama Iqbal Open University (AIOU) is the pioneer of introducing the concept of distance learning in Pakistan and is actively engaged in this since 1974 (AIOU, 2011). According to Reddi and Mishra (2005) another form of e-learning through the use of radio, television, and print media has remained popular mode of disseminating distance level education in Pakistan. However, Virtual University (VU), a joint project of government and private sector was established in 2002 (VU, 2011). It is VU that has effectively capitalized upon broadcasting media and Internet to impart education. Later in Year 2003, French Embassy (Pakistan) in collaboration with COMSATS initiated delivery of French Language course online.

The use of technology in Pakistan for distance learning has remained associated to educational sector alone, which is sometimes referred to as "Open Schooling", however a training journey in the country's other organizational sectors (public/ private, service/ manufacturing etc) is still to be discovered at length. Even though, e-learning must be present in some form in few of the organizations, a major portion of the industry has still to unfold the hidden treasures.

\subsection{IBP-Superior Qualification (ISQ)}

Institute of Bankers Pakistan (IBP) was established in 1951 as a not-for-profit entity. The primary objective of the institute is to help financial sector through training and development. Since 1951, IBP has been administrating Banking Diploma Program (DAIBP) that has recently been renamed and revised to IBP-Superior Qualification (ISQ). ISQ is fully recognised by State Bank of Pakistan and financial sector including banking sector of Pakistan.

ISQ is divided into three levels i) Junior Associateship of IBP (JAIBP), Associateship of IBP (AIBP) and Fellowship of IBP (FIBP). Successful candidates expect a rise in salary, promotion, cash rewards, increased employability and other recognition. A very high number of bankers register for IBP program. IBP facilitate students through its published material such as it text books, past papers and coaching classes.

However, students face following issues with ISQ Program, despite all the efforts put by IBP.

- The lack of coaching facility to the majority of students as it is only being offered at Head Office as per coaching schedule for summer 2012 available on official website IBP (2012).

- The demanding nature of the job that leaves little energy to study or for self-growth.

The research in given context, aims to investigate the prospects of e-learning based ISQ program, which will 
definitely overcome most of the issues pertaining to students that are listed above.

\subsection{Theories on Technology Acceptance}

A brief summary of the leading theories in the field of technology acceptance are shown in the Table 1:

Table 1. Summary of the major theories on Technology Acceptance

\begin{tabular}{|c|c|c|}
\hline Author & Name of the Theory & Basic Concept \\
\hline Ajzen (1985) & Theory of Planned Behavior (TPB) & $\begin{array}{l}\text { This theory places the intention of humans as the basis for the behavior. } \\
\text { Though it is an extension of Theory of Reasoned Action (TRA) it differs by } \\
\text { adding variable of perceived behavioral control (PBC). }\end{array}$ \\
\hline $\begin{array}{l}\text { Taylor \& Todd } \\
\text { (1995) }\end{array}$ & $\begin{array}{l}\text { Decomposed Theory of Planned } \\
\text { Behavior (DTPB) - } \\
\text { Taylor \& Todd's contribution }\end{array}$ & It is an extension to TPB by proposing decomposing its constructs. \\
\hline $\begin{array}{l}\text { Pavlou \& } \\
\text { Fygenson } \\
(2006)\end{array}$ & $\begin{array}{l}\text { Decomposed Theory of Planned } \\
\text { Behavior (DTPB) - } \\
\text { Pavlou \& Fygenson's contribution }\end{array}$ & It is also an extension of TPB to predict e-commerce process. \\
\hline Davis (1986) & Technology Acceptance Model (TAM) & $\begin{array}{l}\text { It is an extension of TRA. It explains individuals' acceptance of information } \\
\text { technology with reference to determinants of computer acceptance. }\end{array}$ \\
\hline Triandis (1979) & The Model of PC Utilization (MPCU) & $\begin{array}{l}\text { This model in the form of a framework describes behavior occurrence } \\
\text { process and the variables that influence the human behavior }\end{array}$ \\
\hline $\begin{array}{c}\text { Venkatesh et al. } \\
(2003)\end{array}$ & $\begin{array}{l}\text { The Unified Theory of Acceptance } \\
\text { and Use of Technology (UTAUT) }\end{array}$ & $\begin{array}{l}\text { UTAUT is the synthesis of eight dominant models that have been used } \\
\text { to explain the behavior of technology acceptance. }\end{array}$ \\
\hline
\end{tabular}

Davis (1986) building on the work of Theory of Reasoned Action (TRA) established Technology Acceptance Model (TAM). It develops a causal relationships between system design features, perceived usefulness, perceived ease of use, attitude toward using, and actual usage behaviour. Figure 2 shows the latest Technology Acceptance Model (TAM) proposed by Davis (1989).

Fig 2: Davis (1989) Technology Acceptance Model (TAM)

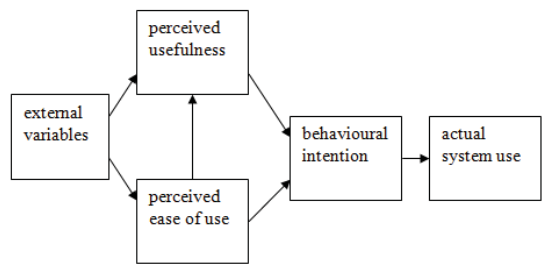

\section{The research model and hypotheses}

The study proposes a research model that it attempts to explain and predict the employees' intention to use e-learning. The model is devised in the light of the TAM model (see Fig 3).

Fig. 3: Research Model

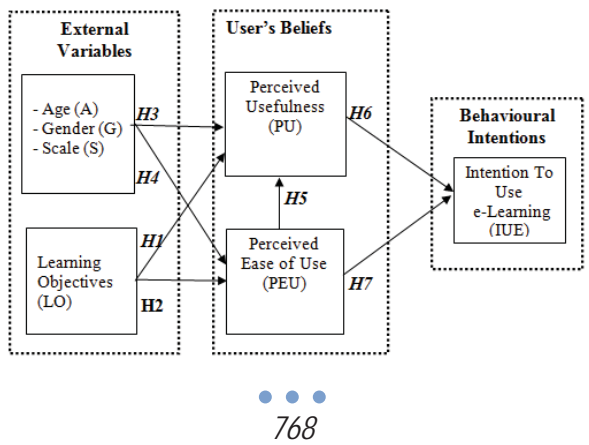


In the light of the research model following hypotheses are postulated:

H1: There exists a positive relationship between Learning Objectives (LO) and the perceived usefulness (PU) of the course.

$H 2$ : There exists a positive relationship between Learning Objectives (LO) and the perceived ease of use (PEU) of the course.

H3: Demographic factors have no relationship with perceived usefulness (PU).

H4: Demographic factors have no relationship with perceived ease of use (PEU).

H5: There exists a positive relationship between Perceived ease of use (PEU) and perceived usefulness (PU).

H6: There exists a strong positive relationship between Perceived usefulness (PU) and intention to use e-learning system (IUE).

H7: There exists a strong positive relationship between (PEU) and intention to use e-learning system (IUE).

\section{Methodology}

\subsection{Population and Sample}

The total population of the study were all the employees that are registered as student with Institute of Bankers Pakistan for IBP-Superior Qualification (ISQ) course. A convenient random sample $(n=172)$ was used out of all the 41 banks operating in Pakistan.

\subsection{Data Collection Method}

Online survey software was used to solicit the responses. Emails were sent to the head offices of all the 41 banks. Telephonic calls were made in order to pursue the survey filling out. All the filled in responses were downloaded used for analysis.

\subsection{Instrumentation}

The online survey software provided the facility to make important questions as mandatory to reply. Hence all the filled in questionnaires $(n=172)$ were valid and good for analysis.

The questionnaire was comprised of a total 19 questions. There were 3 questions on demographic factors such as age, gender and pay scale, 4 questions on Perceived Usefulness (PU), 4 questions on Learning Objectives (LO), 4 questions on Perceived ease of Use (PEU), 4 questions on Intention to Use e-learning (IUE). The respondents were asked to respond on a 5 points Likert Scale with $5=$ Strongly Agree and $1=$ Strongly Disagree.

\subsection{Data Analysis Techniques}

In order to check and understand the data at length a descriptive statistics is used. Correlation and Regression analysis are used to understand the underlying relationship between variable. No violation of the assumption was noticed.

\subsection{Reliability Measurement}

Cronbach Alpha is used to measure the reliability of the instrument (see table.2). The results shows that the instrument is highly reliable with a being 0.832 . The alpha values for LO, PEU, PU and IUE are $0.823,0.782,0.735$ and 0.870 respectively. Alpha values higher than 0.70 is generally considered reliable (Tabachnick and Fidell, 2007), hence we can call this instrument as a reliable.

Table 2: Reliability of the scale

\begin{tabular}{|l|c|c|}
\hline & Cronbach's Alpha & No of Items \\
\hline Learning Objectives (LO) & 0.823 & 4 \\
\hline Perceived Ease of Use (PEU) & 0.782 & 4 \\
\hline
\end{tabular}




\begin{tabular}{l|c|c|} 
Perceived Usefulness (PU) & 0.735 & 4 \\
\hline Intention to Use e-learning (IUE) & 0.870 & 4 \\
\hline & 0.832 & 16 \\
Alpha value $>0.70$ shows a reliability.
\end{tabular}

\section{Results}

\subsection{Descriptive statistics of the sample}

The respondents survey profile is given in the Table 3 . The majority of the respondents were male (78\%) while female were only $22 \%$. A good majority (89\%) of the respondents were below the age of 50 . However, there the respondents between the age bracket ' 25 - 30' years and '41-50' were almost equal in size with $26 \%$ and $28 \%$ representation respectively. On the basis of employment scale/position in hierarchy, $40 \%$ of the respondents were on Scale $-18,35 \%$ on Scale 16-17 and 18\% between the Scale 19-20. Only 3\% respondents were below the Scale-16 who were registered with ISQ and have given their responses. Full demographic summary of the respondents is given in table 3.

\subsection{Mean and Standard Deviation of the Sample}

Mean and Standard Deviation of the variables is presented in table 4. The data indicates that the average scale of the respondents is 2.84 which around pay scale (grade) 18. The respondents have reported a high level of desire to fulfill their personal learning objectives with an average of 4.4895. The respondents also believe that the adoption of e-learning courses would facilitate them with more comfort to use (PEU=4.6090) and would result in enhanced usefulness $(\mathrm{PU}=4.6140)$. Overall the respondents have shown a high level of intention to use the e-learning based courses with a mean value of 4.4535. The standard deviation of S, PU, PEU \& IUE is low as compared to LO where it is 1.39680.

Table 3: Demographic Summary of respondents

\begin{tabular}{|l|c|c|c|c|c|c|}
\hline Demographic Variables & \multicolumn{2}{|c|}{ Gender } & \multicolumn{2}{c|}{ Age } & \multicolumn{2}{c|}{ Position / Scale } \\
\hline & $\mathrm{F}$ & $\mathrm{P}(\%)$ & $\mathrm{F}$ & $\mathrm{P}(\%)$ & $\mathrm{F}$ & $\mathrm{P}(\%)$ \\
\hline Male & 134 & 77.90 & & & & \\
\hline Female & 38 & 22.10 & & & & \\
\hline$<25$ years & & & 33 & 19.20 & & \\
\hline $25-30$ years & & & 45 & 26.20 & & \\
\hline $31-40$ years & & & 27 & 15.70 & & \\
\hline $41-50$ years & & & 48 & 27.90 & & \\
\hline$>50$ years & & & 19 & 11.00 & & \\
\hline$<16$ scale & & & & & 5 & 02.90 \\
\hline $16-17$ scale & & & & & 60 & 34.90 \\
\hline 18 scale & & & & & 70 & 40.70 \\
\hline $19-20$ scale & & & & & 31 & 18.00 \\
\hline$>21$ scale & & & & & 6 & 03.50 \\
\hline Total & 172 & 100 & 172 & 100 & 172 & 100.00 \\
\hline
\end{tabular}

Note: F: frequency P: percentage (\%)

Table 4: Mean and Standard Deviation of Technology Acceptance Variables

\begin{tabular}{|l|c|c|}
\hline \multicolumn{1}{|c|}{ Research Variables } & Mean & Std. Deviation \\
\hline Scale (S) & 2.8430 & 0.06667 \\
\hline Learning Objectives (LO) & 4.4895 & 1.39680 \\
\hline Perceived Usefulness (PU) & 4.6140 & 0.73749 \\
\hline Perceived Ease of Use (PEU) & 4.6090 & 0.69519 \\
\hline Intention to Use e-learning (IUE) & 4.4535 & 0.73201 \\
\hline
\end{tabular}




\subsection{Pearson Correlations}

The results of the Pearson correlations are presented in table 5. A brief summary of the results of Pearson Correlation is given below:

- There exits no significant relationship between Age $(A)$ and Gender $(G)$

- There exits a weak negative correlation ( $a=-210$ significant at 0.01 ) between Gender and Pay Scale (S).

- There exits a weak positive relationship ( $a=.198$ significant at 0.01$)$ between Pay Scale $(S)$ and Age (A).

- There exits a weak negative relationship ( $a=-.288$ significant at 0.01$)$ between Learning Objective (LO) and Gender (G).

- There exits a weak negative relationship (a=-.291 significant at 0.01) between Learning Objective (LO) and Age (A).

- There exits a weak negative relationship ( $a=-.296$ significant at 0.01 ) between Perceived Utility (PU) and Age (A).

- There exits a strong positive relationship ( $a=.296$ significant at 0.01$)$ between Perceived Utility (PU) and Learning Objective (LO).

- $\quad$ There exits a weak negative relationship (a=-.258 significant at 0.01 ) between Perceived ease of Use (PEU) and Scale (S).

- There exits a weak positive relationship ( $a=.172$ significant at 0.05$)$ between Perceived ease of Use (PEU) and Learning Objectives (LO).

- There exits a weak positive relationship ( $a=.222$ significant at 0.01 ) between Intention to Use e-learning (IUE) and Learning Objectives (LO).

Table 5: Pearson Correlation

\begin{tabular}{|l|c|c|c|c|c|c|c|}
\hline & G & A & S & LO & PU & PEU & IUE \\
\hline Gender (G) & 1 & & & & & & \\
\hline Age (A) & .080 & 1 & & & & & \\
\hline Scale (S) & $-.210^{* *}$ & $.198^{* *}$ & 1 & & & & \\
\hline Learning Objective (LO) & $-.288^{* *}$ & $-.291^{* *}$ & -.142 & 1 & & & \\
\hline Perceived Utility (PU) & -.147 & $-.296^{* *}$ & -.095 & $.751^{* *}$ & 1 & & \\
\hline Perceived Ease of Use (PEU) & .038 & .003 & $-.258^{* *}$ & $.172^{*}$ & $.229^{* *}$ & 1 & \\
\hline Intention to Use E-learning (IUE) & -.043 & .111 & -.066 & $.222^{* *}$ & $.216^{* *}$ & $.465^{* *}$ & 1 \\
\hline
\end{tabular}
**. Correlation is significant at the 0.01 level (2-tailed).
*. Correlation is significant at the 0.05 level (2-tailed).

- $\quad$ There exits a weak positive relationship ( $a=.216$ significant at 0.01$)$ between Intention to Use e-learning (IUE) and Perceived Utility (PU).

- There exits a moderate positive relationship ( $a=.465$ significant at 0.01 ) between Intention to Use e-learning (IUE) and Perceived Ease of Use (PEU).

\subsection{Regression Analysis}

\subsubsection{Perceived Utility (PU)}

The regression analysis indicates a 56\% variance in Perceived Utility (PU) due to Learning Objectives (LO), Age (A), Gender (G). Where as only $5.2 \%$ variance in Perceived Utility (PU) due to Perceived Ease of Use (PEU).

Table 7: Regression Analysis

\begin{tabular}{|l|c|c|c|c|}
\hline & $\mathbf{R}^{2}$ & Adj. $^{2}$ & T- value & $\boldsymbol{p}$ Value \\
\hline $\mathrm{LO}(\mathrm{a}), \mathrm{A}(\mathrm{a}), \mathrm{G}(\mathrm{a}), \mathrm{S}(\mathrm{a})-\mathrm{PU}(\mathrm{b})$ & .564 & .554 & 54.062 & $.000^{\mathrm{a}}$ \\
\hline & $\circ 71$ &
\end{tabular}




\begin{tabular}{|l|l|l|l|l|}
\hline PEU(a) - PU(b) & .052 & .047 & 9.370 & $.003 a$ \\
\hline $\begin{array}{l}\text { a. Predictors: } \\
\text { b. Dependent Variable: }\end{array}$ \\
\hline Note: shows $\beta$ value where $p<0.001$ \\
\hline
\end{tabular}

\subsubsection{Perceived Ease of Use (PEU)}

The results show that $R^{2}$ is 0.127 when Perceived Ease of Use (PEU) is regressed by Learning Objectives (LO), Age (A), and Scale (S).

Table 8: Regression Analysis

\begin{tabular}{|l|c|c|c|c|}
\hline & $\mathbf{R}^{2}$ & Adj. $\mathbf{R}^{2}$ & T- value & $\boldsymbol{p}$ Value \\
\hline $\mathrm{LO}(\mathrm{a}), \mathrm{A}(\mathrm{a}), \mathrm{G}(\mathrm{a}), \mathrm{S}(\mathrm{a})-\mathrm{PEU}(\mathrm{b})$ & .127 & .106 & 6.088 & $.000^{\mathrm{a}}$ \\
\hline $\begin{array}{l}\text { a. Predictors: } \\
\text { b. Dependent Variable: }\end{array}$ \\
\hline Note: shows $\boldsymbol{\beta}$ value where $\mathrm{p}<0.001$ \\
\hline
\end{tabular}

\subsubsection{Intention to Use (IUE)}

The results show the $\mathrm{R}^{2}$ value as .229 when IUE is regressed by PU and PEU.

Table 9: Regression Analysis

\begin{tabular}{|c|c|c|c|c|}
\hline & $\mathbf{R}^{2}$ & Adj. $R^{2}$ & $T$-value & $p$ Value \\
\hline PU(a), PEU(a) - IUE (b) & 229 & .220 & 25.13 & $.000^{\mathrm{a}}$ \\
\hline $\begin{array}{l}\text { a. Predictors: } \\
\text { b. Dependent Variable: }\end{array}$ & & & & \\
\hline
\end{tabular}

\section{Discussion}

The overall results indicate that:

H1: There exists a strong positive relationship between Learning Objectives (LO) and the perceived usefulness (PU) of the course. Hence we will accepted $\mathrm{H1}$.

$\mathrm{H} 2$ : The relationship between Learning Objectives (LO) and the perceived ease of use (PEU) of the course is also positive, again we will accept $\mathrm{H} 2$.

H3: Demographic factors have no relationship with perceived usefulness (PU). Again proving that our hypothesis was right, we will accept $\mathrm{H} 3$.

H4: The relationship between Demographic factors ( $G$ \& S) have no significant relationship with perceived ease of use (PEU), where as Age (A) has a low positive relationship with PEU. Hence we will also accept $\mathrm{H} 4$.

H5: There exists a positive relationship between Perceived ease of use (PEU) and perceived usefulness (PU), indicated with $\beta=.229$. Hence we will accept $\mathrm{H} 5$.

H6: There exists a positive relationship between Perceived usefulness (PU) and intention to use e-learning system (IUE) indicated with $\beta=.115$. Hence we will accept $\mathrm{H} 6$.

H7: There exists a strong positive relationship between (PEU) and intention to use e-learning system (IUE) indicated with $\beta=.439$. Hence we will accept $\mathrm{H} 7$.

The graphical representation of $\beta$-values is indicated in figure 4 .

\section{Conclusions}

The results of the study indicate good prospects for introducing e-learning based ISQ courses. The employees consider it a superior with enhanced features of usefulness and ease of use. The learning objectives of the employees have remained the most significant contributor towards their motivation towards acceptance of e-learning based courses. 
However, age, gender and position (scale) of the employees have little or no affect on their selection to e-learning courses, except age having a moderate affect on ease of use.

A good majority of the respondents are below the age group 40 and have shown promising inclination towards these e-learning based courses. They are in the start of the career. They consider learning as a tool to growth. Their busy schedule at work is also one the compelling reason for them to adopt e-learning based course.

Fig 4: Graphical representations of $\beta$-values

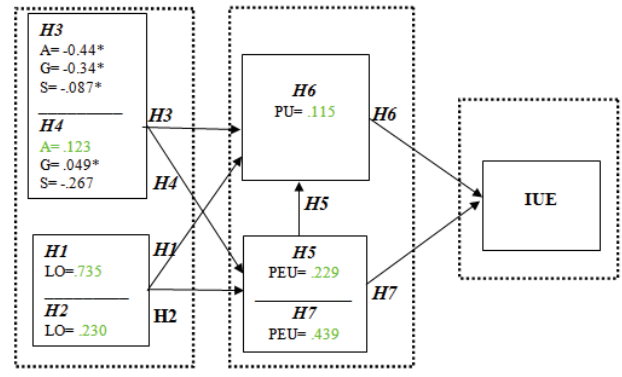

${ }^{*} B$ value is insignificant

\section{Implications of the findings}

The study unfolds bright prospects of e-learning based courses in Pakistan. It indicates the great urge of the employees towards learning and enhancing their skills while remaining employed. It will help to provide skilled labor not only to financial sectors but also other related sectors. Institute of Bankers Pakistan (IBP) can introduce an e-learning based ISQ course which will help them to increase their customer base, customer awareness and ultimately result into significant financial benefits.

\section{Limitations}

The current study focuses on the ISQ course offered by the Institute of Bankers Pakistan (IBP), a professional qualification for banking sector. Similar studies may be conducted on other related sectors in order to fully capitalize upon the benefits of e-learning.

\section{References}

AIOU (2011), 'Establishment' [Online], Allama Iqbal Open University, Available http://www.aiou.edu.pk/Establishment.asp Accessed on March 4, 2011

Ajzen., I. (1985) From Intentions to Actions: A Theory of Planned Behaviour. Edited by Khul, J. and Beckmann, J. Springer-Verlag, and Berlin Heidlberg. New York Tokyo.

Allen. M (2012), e-Learning Annual - 2012, Pfeiffer, An Imprint of Wiley, San Francisco. 1

ASTD (2010), State of the art Industry report 2010, [Online], American Society for Training and Development, Available http://www.astd.org/TD/Archives/2010/Nov/Free/1110_2010+State+of+the+Industry.htm Accessed on 30/11/ 2010.

Bell. J (2007), "E-Learning: Your flexible development friend", Emerald Group Publishing Limited, Vol. 21 No. 6, pp. 7-9

Cheol H. Oh (2003). Information Communication Technology and the New University: A View on eLearning Annals of the American Academy of Political and Social Science, Vol. 585, Higher Education in the Twenty-First Century (Jan., 2003), pp. 134-153

Clark, R.C and Mayer, R.E (2011). E-Learning and the Science of Instruction, 3rd Edition, Pfeiffer, An imprint of Wiley.

Davis, F.D. (1986) Technology Acceptance Model for Empirical Testing New End-User Information System: Theory and Results. Cambridge, MA: MIT Sloan School of Management.

Davis, F.D. (1989). "Perceived usefulness, perceived ease of use, and user acceptance of information technology". MIS Quarterly, 13 (3), pp. 318-340.

Flett. D, Alpassa. F, Humphriesa. S, Masseyb. C, Morrissc. S, Longd.N (2004), The technology acceptance model and use of technology in New Zealand dairy farming, Agricultural Systems, Elsevier Publication, Volume 80, Issue 2, pp 199-211

IBP (2010), ISQ Over view, Program Structure, [Online] The Institute of Bankers Pakistan, Available http://www.ibp.org.pk/ISQOverview.aspx Accessed on April 8, 2011.

King W.R \& He. J ( 2006) A meta-analysis of the technology acceptance model, Information \& Management, Elsevier Publication, 
Volume 43, Issue 6, pp 740-755

Lee. B-C, Yoon. J-O, Lee. I (2009), Learners' acceptance of e-learning in South Korea: Theories and results, Computers \& Education, Elsevier publication, Volume 53, Issue 4, pp 1320-1329

Pailing M (2002), "E-Learning: Is it really the best thing since sliced bread? Industrial and Commercial Training, Guilsborough., Vol 34 , No $4 / 5$, pp. 155, 5.

Pai. F \& Huangb. K.I (2011), Applying the Technology Acceptance Model to the introduction of healthcare information systems, Technological Forecasting and Social Change, Elsevier Publication, Volume 78, Issue 4, pp 650-660

Pavlou, P. and Fygenson, M. (2006) Understanding and predicting electronic commerce adoption: An extension of the Theory of planned behaviour. MIS Quarterly 30(1) 115- 149.

Reddi U.V. and Mishra S. (Eds.) (2005) 'Perspectives on Distance Education:Educational Media in Asia', [Online] Commonwealth of Learning, Vancouver, Available http://www.col.org/SiteCollectionDocuments/EdMedia_Asia.pdf Accessed on Feb 22, 2011.

Russell, T.L (2005), No significant difference, Available http://www.nosignificantdifference.org/ Accessed on March 28, 2011.

Ryder, M \& Wilson,B.G (1996), Affordance and constraints of the internet for learning and instruction. Paper presented at Association for Educational Communications Technology (AECT) on February 14-18, 1996.

Sloman, M. (2005), Reflections on the 2005 training and development survey: E-learning a clear picture emerges, [Online], CIPD, London. Available www.cipd.co.uk/surveys Accessed on May 09, 2005.

Straub. D, Keila. M, Brennerb. W (1997), Testing the technology acceptance model across cultures: A three country study, Information \& Management, Elsevier Publication, Volume 33, Issue 1, 7, pp. 1-11

Šumak. B, Heričko. M, Pušnik. M (2011), A meta-analysis of e-learning technology acceptance: The role of user types and e-learning technology types, Computers in Human Behavior, Elsevier publication, Volume 27, Issue 6, pp 2067-2077.

Tabachnick, B., Fidell, L., (2007). Using Multivariate Statistics, $5^{\text {th }}$ Edition. Allyn and Bacon Publication, Boston, USA.

Taylor, S., and Todd, P. (1995) Decomposition and crossover effects in the theory of planned behaviour: A study of consumer adoption intentions. International Journal of Research in Marketing, 12(2) 137-155.

Triandis, H. (1979) Values, Attitudes, and Interpersonal Behaviour, Nebraska Symposium on Motivation, 27, 195-259.

Venkatesh, V., Morris, M., Davis, G., and Davis, F. (2003) User acceptance of information technology: toward a unified view. MIS Quarterly, 27 (3) 425- 478.

VU (2011), About Us, Virtual University, Available from http://www.vu.edu.pk/ Accessed on Feb 21, 2011

Webster D. (2005) Learning about E-Learning, [Online], Knowledge Presenter Kookaburra Studio Pvt. Ltd. Available http://www.knowledgepresenter.com/kpuniversity/2005/index.html?http://www.knowledgepresenter.com/kpuniversity/2005/whitep apers/index.html?http://www.knowledgepresenter.com/kpuniversity/2005/whitepapers/lal.htmAccessed on May 22, 2012: 